\title{
Relative improvements in road mobility as compared to improvements in road accessibility and urban growth: a panel data analysis
}

\begin{abstract}
Previous studies revealed that the development of road infrastructure contributed positively to urban growth. However, the demand for and supply of different road types may change according to the level of urbanization, and this might have a significant impact on urban growth. The objectives of this study were twofold. First, to determine the investment level needed for different road types to facilitate urban growth at different levels of urbanization. Second, to understand how the development of different road types promotes export-led urban growth. We apply a fixed-effects panel linear regression analysis on a panel of 60 countries over the period of 1980-2010. The evidence presented in this study suggests that improvements in road mobility promoted export-led urban growth in countries with a low level of urbanization. This implies that policies to facilitate export should be executed in conjunction with high-mobility road network expansion to increase urbanization, especially in countries with a low level of urbanization that commonly suffer from low growth rates and that have a low level of high mobility road networks. Such expansion in road mobility is required to fulfil demands for long-distance travel to transport people from rural to urban areas. In contrast, in countries with a high level of urbanization, more investment is needed to develop roads with high accessibility. Such roads are needed to fulfil daily travel demands as a consequence of urban sprawl and decentralization of employment and populations. Moreover, the evidence shows that per capita education expenditure and physical capital stock per worker contributed to urban growth.
\end{abstract}

Keyword: High mobility roads; High accessibility roads; Export-led urban growth; Fixedeffects panel linear regression 